\title{
Role of B-type natriuretic peptide in diagnosis of coronary artery disease
}

\author{
Bedrettin Boyraz $^{1} \odot$, Ferit Onur Mutluer ${ }^{2} \odot$, Hakan Çakır $^{3} \odot$, Dursun Topal $^{3} \odot$, Mehmet Demir $^{3} \odot$, Fahri $^{\circ}$ \\ Er $^{3} \odot$, Tezcan Peker $^{4} \odot$, Mustafa Yılmaz $^{5} \odot$, Alkame Akgümüş̧ $^{6}$, Erhan Tenekecioğlu ${ }^{3} \odot$ \\ ${ }^{1}$ Department of Cardiology, Tatvan State Hospital, Bitlis, Turkey \\ ${ }^{2}$ Department of Cardiology, Koç University School of Medicine, İstanbul, Turkey \\ ${ }^{3}$ Department of Cardiology, University of Health Sciences, Bursa Yüksek Ihtisas Training and Research Hospital, Bursa, Turkey \\ ${ }^{4}$ Department of Cardiology, Bursa Doruk Hospital, Bursa, Turkey \\ ${ }^{5}$ Department of Cardiology, Uludağ University School of Medicine, Bursa, Turkey \\ ${ }^{6}$ Department of Cardiology, Gemlik State Hospital, Bursa, Turkey
}

DOI: $10.18621 /$ eurj.447914

\begin{abstract}
Objectives: B-type natriuretic peptide (BNP) has been extensively studied as a biomarker in heart failure. There is clear benefit of BNP in diagnosis and risk stratification of several cardiac diseases including acute coronary syndromes. Our aim was to evaluate diagnostic role of changes in BNP levels with exercise in coronary artery disease (CAD).

Methods: Fifty-one patients underwent exercise stress testing (EST) for suspected CAD and consequently underwent coronary angiography (CA) were prospectively enrolled. Patients with and without at least one significant diameter stenosis in major epicardial arteries (CA+ and CA-) versus patients with and without evidence of myocardial ischemia during exercise stress testing (EST+ and EST-) were classified into 4 groups, respectively (Group 1, CA+/EST+; group 2, CA+/EST-; group 3, CA-/EST+; and group 4, CA-/EST-). All patients underwent EST. Blood was drawn from patients for determination of BNP levels 10 minutes prior to, 10 minutes after and 4 hours after EST.

Results: EST parameters other than the parameters signifying myocardial ischemia didn't differ significantly among groups $(p>0.05)$. Pre-exercise, post-exercise and 4h-post exercise BNP values were significantly higher in group 1 and group 2 compared to group 3 and group 4 ( $p<0.05$ for all comparisons between the groups for pre-exercise, post-exercise and 4h-post exercise BNP). Exercise-induced increases in BNP were higher in group 1 and group 2. Patients with significant CAD involving LAD demonstrated higher basal and exercise-induced $\mathrm{BNP}$ as well as BNP increases, irrespective of the EST result.

Conclusions: Basal, maximal-exercise and post exercise BNP values predicted CAD, as well as CAD involving LAD irrespective of ischemic changes in EST. Our results point out potential role of BNP as an adjunct to EST in diagnosis and management of CAD.
\end{abstract}

Keywords: Natriuretic peptide, coronary artery disease, exercise stress test, myocardial ischemia

Received: July 25, 2018; Accepted: July 29, 2018; Published Online: July 30, 2018

Address for correspondence: Erhan Tenekecioğlu, MD., Associate Professor, University of Health Sciences, Bursa Yüksek İhtisas Training and Research Hospital, Department of Cardiology, Bursa, Turkey

E-mail: erhantenekecioglu@yahoo.com,Tel: +902242955000,Fax:+902242756767

Copyright (C) 2019 by The Association of Health Research \& Strategy

Available at http://dergipark.gov.tr/eurj 
$\mathrm{T}$ he idea that the heart is an endocrin organ was suggested by Kisch et al. [1] in 1956 with demonstration of secretory granules in atria of pigs. These secretory granules were later demonstrated to contain atrial natriuretic peptide (ANP). Subtypes and physiology of these peptides are studied extensively and have been defined since then. There are 3 main subtypes of natriuretic peptides: ANP, which is mainly secreted in atria; B-type natriuretic peptide (BNP) (known as brain natriuretic peptide), which is mainly secreted from ventricles [2]; Type-C natriuretic peptide which is mainly secreted from vascular endothelium, central nervous system and kidneys, and intestinal-type natriuretic peptide, secreted from gastrointestinal system mucosa [3].

Brain natriuretic peptide is synthesized in ventricle as a pro-BNP form consisting of 108 amino acids. This propeptide is later cleaved into active form, BNP, consisting of 32 amino acids and N-terminal pro-BNP by peptidases. Especially BNP has been extensively studied as a biomarker in mainly heart failure, and demonstrated prognostic significance in several different clinical settings. While there is clear benefit of BNP in diagnosis and risk stratification of several cardiac diseases including patients with acute coronary syndromes [4] and previous myocardial infarction [5], there is compelling evidence regarding role of this biomarker in management of transient myocardial ischemia in patients without concommitant structural heart disease [6].

Coronary artery diease (CAD) encompasses a wide range of clinical subsets from ST segment elevation myocardial infarction (STEMI) to stable angina pectoris. Common biomarkers used for diagnosis and management of CAD with acute presentation (unstable angina pectoris, non-ST segment elevation acute coronary syndrome, ST segment elevation acute coronary syndrome) such as creatin kinase-MB (CK-MB) and troponins are released into blood stream from irreversibly damaged myocardial tissue. In contrast, BNP is mainly secreted actively from reversibly damaged myocardial tissue. As a result, BNP was beneficial in assessing physiologic consequences of ischemia and infarct rather than the extent of damaged myocardial tissue. Our aim in this study was to evaluate diagnostic role of changes in BNP levels with exercise in CAD.

\section{METHODS}

\section{Patients}

This study was conducted in Bursa Yüksek İhtisas Training and Research Hospital. The patients were selected from patients who admit to outpatient clinic with signs and symptoms warranting exercise stress testing (EST). Twenty-six patients (18 males, 8 females, mean age $54.7 \pm 1.7$ years) with at least $50 \%$ narrowing in at least one of the 3 major epicardial coronary arteries, and 25 patients (15 males, 10 females; mean age $52.5 \pm 1.8$ years) with no narrowing or diameter stenosis $<50 \%$ in any of the major epicardial arteries were enrolled in this clinical study. Patients with severe valvular disease, New York Heart Association (NYHA) class III-IV heart failure, myocardial infarction in the last 2 weeks, with hepatic and/or renal dysfunction and patients with significant systemic disease other than diabetes mellitus (DM) were excluded from this study.

Study patients underwent detailed assessment for cardiovascular risk factors. Detailed past medical history, physical examination and laboratory parameters were evaluated for this purpose. Electrocardiography (ECG), chest X-ray, fasting plasma glucose, total cholesterol, LDL cholesterol, HDL cholesterol levels; hemoglobin, hematocrit, white blood cell counts were assessed.

All patients underwent standard transthoracic echocardiographic examination before EST. All patients underwent EST with standart Bruce protocol. Blood was drawn from patients for determination of BNP levels 10 minutes prior to, 10 minutes after and 4 hours after EST. The study protocol was approved by Bursa Yüksek İhtisas Training and Research Hospital ethical committee. Informed consent was obtained from all patients prior to enrollment in the study protocol.

\section{Exercise Stress Testing}

EST was performed in accordance with relevant guidelines on a treadmill. Beta blockers were witheld for at least 2 days, and digoxin was witheld for at least 2 weeks prior to EST. Electrocardiography, heart rate and blood pressure parameters and maximal exercise capacity in METs were recorder. At least 1-mm horizontal or downsloping ST-depression $60-80 \mathrm{msecs}$ 
after the end of the QRS complex, bundle branch blocks triggered by ischemia, atrial or ventricular dysrhythmias during EST was accepted as suggestive of ischemia.

\section{Echocardiography}

Echocardiography was performed on a 3.5 Mhz probe with a Vivid 7 Pro machine (General Electric, USA) in left lateral decubitus position. Parasternal short axis, long axis, apical 2 chamber, 3 chamber and 4 chamber views were acquired. Left ventricle diastolic functions were assessed with the use of mitral inflow patterns with pulsed-wave Doppler and tissue doppler imaging of basal septal and lateral walls of the left ventricle.

\section{BNP Analysis}

At least $5 \mathrm{cc}$ of blood was drawn by phlebotomy into EDTA-tubes just before starting EST, within 10 minutes following completion of the EST and 4 hours after EST. Biosite Triage BNP test system (San Diego, California, Biosite incorporated) was utilized for determination of BNP levels. BNP levels are analyised and measured by immunoassay method and ersults are read by Triage MeterPlus (Biosite Co, San Diego, CA) in this system. Brain natriuretic peptide levels analyised by this method are affected by hypertension, diabetes, renal failure and chronic obstructive pulmonary disease [7]. Results are reported in picogram $/$ milliliter $(\mathrm{pg} / \mathrm{mL})$. The minimum level of BNP that could be detected by this assay is $5 \mathrm{pg} / \mathrm{mL}$.

\section{Statistical Analysis}

Statistical analysis was performed on statistical software SPSS version 17. Differences between groups with regard to continuous variables were examined by Mann-Whitney U test, differences with regard to categorical variables were examined by Pearson chi-square test and temporal changes in BNP levels were examined with the use of Wilcoxon signed-rank test. Findings were summarized as (percentage, mean, standard deviation). Threshold for statistical significance of the $\mathrm{p}$ value was accepted as $\leq 0.05$.

\section{RESULTS}

Fifty-one patients who admitted to our cardiovascular diseases outpatient clinic, underwent EST for suspected CAD and consequently underwent coronary angiography were prospectively enrolled in this study. Patients with and without at least one significant diameter stenosis in major epicardial arteries (CA+ and $\mathrm{CA}-)$ versus patients with and without evidence of myocardial ischemia during

Table 1. Basal demographic characteristics of the study population

\begin{tabular}{|c|c|c|c|c|c|c|}
\hline & & $\begin{array}{c}\text { Group 1 } \\
(\mathrm{CA}+/ \mathbf{E S T}+)\end{array}$ & $\begin{array}{c}\text { Group } 2 \\
(\mathrm{CA}+/ \mathrm{EST}-)\end{array}$ & $\begin{array}{c}\text { Group } 3 \\
(\mathrm{CA}-/ \mathbf{E S T}+)\end{array}$ & $\begin{array}{c}\text { Group } 4 \\
\text { (CA-/EST-) }\end{array}$ & Total \\
\hline \multicolumn{2}{|c|}{ Age (years) (Mean \pm SD) } & $54.0 \pm 8.5$ & $55.3 \pm 9.0$ & $50.4 \pm 8.8$ & $55.8 \pm 9.4$ & $53.6 \pm 8.9$ \\
\hline \multirow{2}{*}{ Gender, n (\%) } & Male & $8(66.7)$ & $8(57.1)$ & $10(66.7)$ & $7(70)$ & $33(64.7)$ \\
\hline & Female & $4(33.3)$ & $6(42.9)$ & $5(33.3)$ & $3(30)$ & $18(35.3$ \\
\hline \multirow{2}{*}{ Tobacco, n (\%) } & User & $8(66.7)$ & $5(35.7)$ & $2(13.3)$ & $3(30)$ & $18(35.3)^{*}$ \\
\hline & Not user & $4(33.3)$ & $9(64.3)$ & $13(86.7)$ & $7(70)$ & $33(64.7)^{*}$ \\
\hline \multirow{2}{*}{ DM, n (\%) } & Yes & $1(8.3)$ & $3(21.4)$ & $2(13,)$. & $3(30)$ & $9(17.6)$ \\
\hline & No & $11(91.7)$ & $11(78.6)$ & $13(86,)$. & $7(70)$ & $42(82.4)$ \\
\hline \multirow{2}{*}{ HT, n (\%) } & Yes & $3(25)$ & $6(42.9)$ & $5(33.3)$ & $3(30)$ & $17(33.3)$ \\
\hline & No & $9(75)$ & $8(57.1)$ & $10(66.7)$ & $7(70)$ & $34(66.7)$ \\
\hline \multirow{2}{*}{$\begin{array}{l}\text { Total cholesterol, } \\
\text { n (\%) }\end{array}$} & Yes & $8(66.7)$ & $7(50)$ & $5(33.3)$ & $4(40)$ & $24(47.1)$ \\
\hline & No & $4(33.3)$ & $7(50)$ & $10(66.7)$ & $6(60)$ & $27(52.9)$ \\
\hline \multirow{2}{*}{$\begin{array}{l}\text { Family history } \\
\text { for CVD, n (\%) }\end{array}$} & Yes & $5(41.7)$ & $4(28.6)$ & $1(6.7)$ & $2(20)$ & $12(23.5)$ \\
\hline & No & $7(58.3)$ & $10(71.4)$ & $14(93.3)$ & $8(80)$ & $39(76.5)$ \\
\hline
\end{tabular}


Table 2. Exercise stress test findings

\begin{tabular}{|c|c|c|c|c|c|c|}
\hline & $\begin{array}{c}\text { Group 1 } \\
(\mathrm{CA}+/ \mathrm{EST}+)\end{array}$ & $\begin{array}{c}\text { Group } 2 \\
\text { (CA+/EST-) }\end{array}$ & $\begin{array}{c}\text { Group } 3 \\
(\mathrm{CA}-/ \mathrm{EST}+)\end{array}$ & $\begin{array}{c}\text { Group } 4 \\
\text { (CA-/EST-) }\end{array}$ & Total & $p$ value \\
\hline $\begin{array}{l}\text { Achieved maximal } \\
\text { MET }\end{array}$ & $11.3 \pm 2,6$ & $10.6 \pm 3.5$ & $13.1 \pm 3.2$ & $11.8 \pm 3.3$ & $11.7 \pm 3.1$ & 0.77 \\
\hline Resting heart rate & $86.6 \pm 12.0$ & $93.1 \pm 17.6$ & $88.4 \pm 21.0$ & $85.3 \pm 14.9$ & $88.6 \pm 16.8$ & 0.14 \\
\hline Maximal heart rate & $142.1 \pm 20.2$ & $131.8 \pm 18.3$ & $176 \pm 7.5$ & $181.2 \pm 16.4$ & $157.7 \pm 17.3$ & 0.10 \\
\hline $\begin{array}{l}\text { Heart rate recovery } \\
\text { at } 1^{\text {st }} \text { minute }\end{array}$ & $25.5 \pm 10.3$ & $26.6 \pm 8.4$ & $31.4 \pm 10.4$ & $25.7 \pm 14.2$ & $27.5 \pm 10.7$ & 0.65 \\
\hline
\end{tabular}

exercise stress testing (EST+ and EST-) were classified into 4 groups, respectively (Group-1, $\mathrm{CA}+/ \mathrm{EST}+$; group 2, CA+/EST-; group 3, CA-/EST+; and group 4, CA-/EST-). Twenty-six patients (18 males, 8 females, mean age $54.7 \pm 1.7$ years) had at least $50 \%$ narrowing in at least one of the 3 major epicardial coronary arteries (Group 1 and group 2), and 25 patients ( 15 males, 10 females; mean age 52.5 \pm 1.8 years) had no narrowing of more than $50 \%$ in any of the major epicardial arteries (Group 3 and group 4). All patients underwent EST with standart Bruce protocol. Blood was drawn from patients for determination of BNP levels 10 minutes prior to, 10 minutes after and 4 hours after EST.

Patients with and without significant stenoses in epicardial coronary arteries underwent EST and the patients were grouped in a factorial design into EST+ and EST-. Basal demographic properties of the study

Table 3. Transthoracic echocardiography findings

\begin{tabular}{|c|c|c|c|c|c|c|}
\hline & $\begin{array}{c}\text { Group 1 } \\
(\mathrm{CA}+/ \mathbf{E S T}+)\end{array}$ & $\begin{array}{c}\text { Group } 2 \\
(\mathrm{CA}+/ \mathbf{E S T}-)\end{array}$ & $\begin{array}{c}\text { Group } 3 \\
(\mathrm{CA}-/ \mathbf{E S T}+)\end{array}$ & $\begin{array}{c}\text { Group } 4 \\
\text { (CA-/EST-) }\end{array}$ & Total & $p$ value \\
\hline $\begin{array}{l}\text { Left ventricle ejection } \\
\text { fraction }(\%)\end{array}$ & $54.8 \pm 16.3$ & $51.2 \pm 11.4$ & $65.6 \pm 6.0$ & $60.4 \pm 6.8$ & $58.0 \pm 12.0$ & 0.62 \\
\hline $\begin{array}{l}\text { Left ventricle end- } \\
\text { diastolic diameter } \\
\text { (cm) }\end{array}$ & $4.8 \pm 0.5$ & $4.6 \pm 0.3$ & $4.7 \pm 0.5$ & $4.5 \pm 0.3$ & $4.6 \pm 0.4$ & 0.91 \\
\hline $\begin{array}{l}\text { Left ventricle end- } \\
\text { systolic diameter (cm) }\end{array}$ & $3.2 \pm 0.5$ & $3.2 \pm 0.4$ & $2.9 \pm 0.3$ & $3.1 \pm 0.3$ & $3.1 \pm 0.4$ & 0.95 \\
\hline $\begin{array}{l}\text { E-wave amplitude } \\
(\mathrm{m} / \mathrm{sn})\end{array}$ & $0.78 \pm 0.26$ & $0.65 \pm 0.21$ & $0.8 \pm 0.21$ & $0.79 \pm 0.19$ & $0.75 \pm 0.22$ & 0.88 \\
\hline $\begin{array}{l}\text { A-wave amplitude } \\
(\mathrm{m} / \mathrm{sn})\end{array}$ & $0.79 \pm 0.19$ & $0.79 \pm 0.16$ & $0.82 \pm 0.3$ & $0.78 \pm 0.13$ & $0.8 \pm 0.21$ & 0.46 \\
\hline E/A ratio & $1.0 \pm 0.39$ & $0.83 \pm 0.28$ & $1.0 \pm 0.4$ & $1.0 \pm 0.31$ & $1.0 \pm 0.35$ & 0.67 \\
\hline $\begin{array}{l}\text { Left atrium } \\
\text { anteroposterior } \\
\text { diameter }(\mathrm{cm})\end{array}$ & $3.9 \pm 0.4$ & $3.7 \pm 0.36$ & $3.8 \pm 0.43$ & $3.6 \pm 0.21$ & $3.7 \pm 0.36$ & 0.23 \\
\hline $\begin{array}{l}\text { Interventricular } \\
\text { septum end-diastolic } \\
\text { thickness }(\mathrm{cm})\end{array}$ & $1.11 \pm 0.12$ & $1.12 \pm 0.10$ & $1.17 \pm 0.22$ & $1.0 \pm 0.14$ & $1.11 \pm 0.16$ & 0.09 \\
\hline $\begin{array}{l}\text { Posterior wall end- } \\
\text { diastolic thickness } \\
\text { (cm) }\end{array}$ & $0.99 \pm 0.16$ & $1.12 \pm 0.10$ & $1.17 \pm 0.22$ & $1.02 \pm 0.14$ & $1.11 \pm 0.16$ & $<0.05$ \\
\hline
\end{tabular}


Table 4. Coronary angiography findings

\begin{tabular}{lcccc}
\hline Patient number & $\begin{array}{c}\text { Group 1 } \\
\text { (CA+EST+) }\end{array}$ & $\begin{array}{c}\text { Group 2 } \\
\text { (CA+EST-) }\end{array}$ & $\begin{array}{c}\text { Group 3 } \\
\text { (CA-EST+) }\end{array}$ & $\begin{array}{c}\text { Group 4 } \\
\text { (CA-EST-) }\end{array}$ \\
\hline 1-vessel disease & $1(8 \%)$ & $0(0 \%)$ & & 0 \\
2-vessel disease & $2(17 \%)$ & $3(21 \%)$ & 0 & 0 \\
3-vessel disease & $9(75 \%)$ & $11(78 \%)$ & 0 & 0 \\
LAD (\%) & $53 \pm 39$ & $47 \pm 41.6$ & 0 & 0 \\
RCA (\%) & $33.3 \pm 36.7$ & $35.7 \pm 40.3$ & 0 & 0 \\
Cx (\%) & $30.7 \pm 35.3$ & $44.6 \pm 35.5$ & 0 & 0 \\
\hline
\end{tabular}

$\mathrm{CA}=$ coronary angiography, EST $=$ exercise stress test, LAD $=$ left anterior descending coronary artery, $\mathrm{RCA}=$ right coronary artery, $\mathrm{CX}=$ left circumflex coronary artery

patients are summarized in Table 1. When basal demographic characteristics of the study groups are compared, tobacco use was significantly more frequent in group 1 and group 2 compared to the remaining groups. Significant differences between groups with respect to DM, hypercholesterolemia were detected. Family history for cardiovascular disease was significantly more frequent in group 1 and 2 compared to the remaining groups, likewise.

EST findings of the patients are demonstrated in Table 2. No major complications such as ventricular arrhythmias or ST segment elevation were observed. There was no statistically significant difference between groups with regard to maximal achieved MET, resting heart rate, maximal heart rate and heart rate recovery at $1^{\text {st }}$ minute of recovery.

Transthoracic echocardiography findings including left ventricle ejection fraction, end-diastolic and end-systolic diameters, E and A wave amplitudes of transmitral diastolic inflow waves, E/A ratios, left atrium anteroposterior diameter, and end-diastolic septal wall thickness didn't differ between groups. Posterior wall thickness was significantly higher in Group 1 compared to the remaining groups (Table 3). Coronary angiography revealed mainly 3-vessel disease in major epicardial coronary arteries in group 1 and group 2. Table 4 summarizes the severity of CAD in study groups. While left anterior descending coronary artery (LAD) lesions were apparently more dominant in group 1, left circumflex coronary artery (LCX) lesions in addition to LAD lesions were more severe compared to right coronary artery (RCA) lesions in group 2.

BNP levels before (BNP1), after (BNP2) and 4 hours after EST (BNP3) are summarized in Table 5. All values demonstrated significantly different values in group 1 and group 2 compared to group 3 and group 4. However, there were no significant differences when group 1 and group 2 and similarly group 3 and group 4 were compared with each other. Groups with

Table 5. Pre-exercise, post-exercise and 4-hours post-exercise BNP within study groups

\begin{tabular}{|c|c|c|c|c|c|}
\hline & $\begin{array}{c}\text { Group } 1 \\
(\mathbf{C A}+/ \mathbf{E}+)\end{array}$ & $\begin{array}{c}\text { Group } 2 \\
(\mathrm{CA}+/ \mathrm{E}-)\end{array}$ & $\begin{array}{c}\text { Group } 3 \\
(\mathrm{CA}-/ \mathbf{E}+)\end{array}$ & $\begin{array}{l}\text { Group } 4 \\
\text { (CA-/E-) }\end{array}$ & p value \\
\hline BNP1 (pg/ml) & $79.6 \pm 46.8$ & $42.5 \pm 8.68$ & $17.5 \pm 5.8$ & $11.8 \pm 3.76$ & $<0.05$ \\
\hline BNP2 (pg/ml) & $88.8 \pm 42.5$ & $57.9 \pm 12.1$ & $18.8 \pm 7.3$ & $13.0 \pm 3.66$ & $<0.05$ \\
\hline BNP3 (pg/ml) & $34.2 \pm 31.6$ & $41.9 \pm 9.47$ & $15.8 \pm 4.9$ & $10.0 \pm 3.65$ & $<0.05$ \\
\hline $\begin{array}{l}\text { BNP2-BNP1 } \\
(\mathrm{pg} / \mathrm{ml})\end{array}$ & $9.18 \pm 6.02$ & $15.37 \pm 4.85$ & $1.28 \pm 1.66$ & $1.19 \pm 0.5$ & $<0.05$ \\
\hline $\begin{array}{l}\text { BNP3-BNP1 } \\
(\mathrm{pg} / \mathrm{ml})\end{array}$ & $15.4 \pm 4.9$ & $26.8 \pm 11.4$ & $1.57 \pm 0.4$ & $1.1 \pm 0.2$ & $<0.05$ \\
\hline
\end{tabular}

$\mathrm{CA}=$ coronary angiography, EST $=$ exercise stress test 


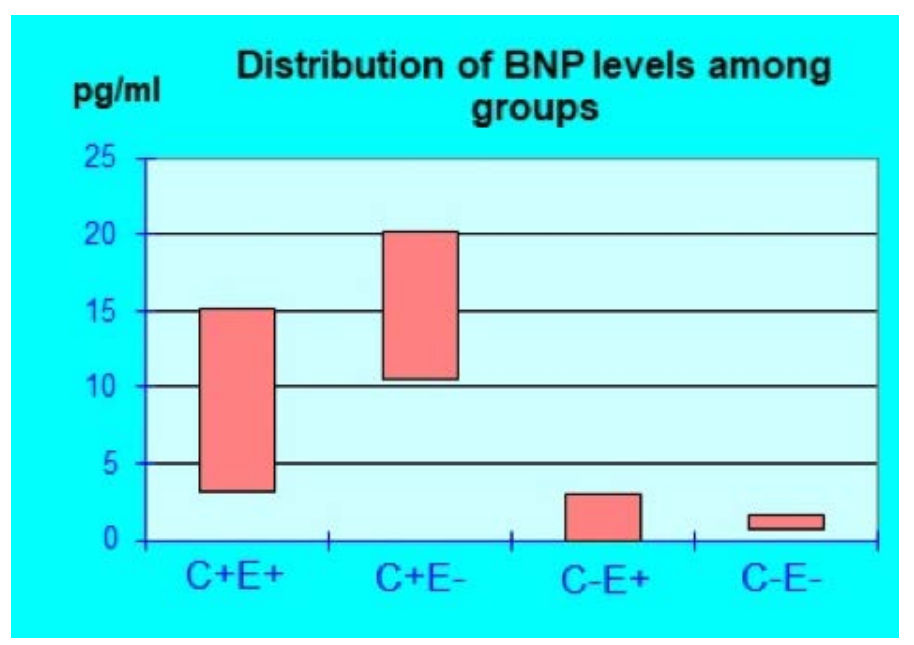

Figure 1. Distribution of BNP levels in study groups. C = coronary angiography, $\mathrm{E}=$ exercise stress test

significant CAD (group 1 and group 2) differed significantly from groups without significant CAD (group 3 and group 4) with regard to response of BNP levels to exercise (Figure 1).

\section{DISCUSSION}

There are 3 main findings of this study; (1) Preexercise BNP levels were significantly higher in patients with CAD compared to patients without significant CAD, (2) Exercise-induced increases in BNP levels are higher in patients with significant CAD, and (3) This difference between patients with and without CAD was independent of exercise induced ST segment depression and result of the EST.

EST retains its position as the first-line diagnostic test in non-invasive assessment of CAD. Onemillimeter of ST segment depression during EST predicts CAD with a sensitivity of $75 \%$ and a specifity of $66 \%$, while 2 -mm ST depression predicts CAD with a $52 \%$ sensitivity and $86 \%$ specifity. EST demonstrated an overall diagnostic performance with a $46 \%$ sensitivity and $40 \%$ specifity in our study.

Diagnostic performance of temporal changes in BNP levels with exercise (BNP-2/BNP-1) was relatively higher compared to EST alone, with a sensitivity of $94 \%$ and a specifity of $70 \%$. Diagnostic accuracy of EST was worse in our study compared to previous studies but diagnostic performance of temporal changes in BNP levels from pre-exercise levels to 10-minute levels was better compared to previous studies. Previous studies demonstrated a $80 \%$ sensitivity and $55 \%$ specifity of this assessment with a BNP cut-off value of $8 \mathrm{pg} / \mathrm{mL}$ [8]. As a result, addition of BNP assessments to EST might improve clinical decision making processes by potentially decreasing expenses, need for advanced invasive and noninvasive tests and complications due to invasive tests.

Several tests and parameters were suggested previously as an adjunct to EST to improve diagnostic accuracy of this test. Gender, age, chest pain, high blood total cholesterole levels, ST-segment depression were all shown to improve diagnostic accuracy of EST. Other predictors that increase EST sensitivity and specifity are exercise capacity, exercise induced angina pectoris, double product value, maximum systolic blood pressure, diabetes mellitus, tobacco use, abnormal resting ECG, high blood pressure, family history of CAD [9]. Similarly, adjunctive use of noninvasive tests such as cardiac tomography or myocardial perfusion scintigraphy were shown to increase accuracy of EST in detecting CAD, albeit with increased costs [10].

BNP is an important indicator of left ventricle dysfunction and myocardial ischemia. This biomarker increases in early phases following myocardial infarction [11]. Bassan et al. [12] previously showed that among patients presenting with ACS without persistent ST segment elevation, BNP levels were above $100 \mathrm{pg} / \mathrm{mL}$ in $70 \%$, although only $50 \%$ of the study patients had elevated CK-MB or troponin I levels elevated at time of presentation. It was suggested in this study that BNP could be used in ruling out noncardiac cause of chest pain as well as in early diagnosis of myocardial ischemia [12].

BNP predicts LV remodelling and mortality following percutaneous coronary interventions in patients with acute coronary syndromes [13]. It similarly predicts heart failure and death independently in long-term follow-up in this patient group [14]. N-terminal BNP (NT-proBNP) is superior to troponin $\mathrm{T}$ in predicting prognosis in ACS patients and could be successfully used as an early indicator of myocardial ischemia. Typical temporal changes in BNP levels include a peak level reached within 24 hours following myocardial infarction and a following plateu. In large MI's a second peak occurs at $5^{\text {th }}$ day 
and this peak is suggested to be an indicator of remodeling [15].

Pre-exercise and peak exercise BNP levels were previously shown to be higher in patients with LAD and CX lesions compared with patients with RCA lesions independent of left ventricle end-diastolic pressures in patients presenting with unstable angina pectoris who had previous history of myocardial infarction [16]. Likewise, increases in BNP levels were higher in patients with LAD lesions compared to patients with $\mathrm{CX}$ and/or RCA lesions. This finding might be related with the size of myocardial territory supplied by the respective epicardial coronary artery.

Exercise-induced acute increases in BNP secretion is shown previously. Marumoto et al showed that increases in BNP levels with exercise as well as peak BNP values reached during maximal exercise were significantly higher in patients with exercise induced ischemia as shown by myocardial perfusion scintigraphy by $\mathrm{Tl} 201$, compared to patients without inducible ischemia [17]. Brain natriuretic peptide was also shown to be an independent predictor of CAD in patients undergoing dobutamine stress echocardiography [18]. N-terminal pro-BNP was similarly found to have higher values and increase significantly more in patients with inducible ischemia by MPS compared to controls without ischemia. These values also correlated with severity of CAD in studies [18]. Another study yielded conflicting results with significantly increased pre-exercise, but not peak BNP values with CAD [16].

Accumulating evidence lead to rise of BNP as a potential candidate in diagnosis and risk stratification of CAD, so that ischemia-induced BNP levels were suggested as a biomarker for ruling-out ischemia, irrespective of left ventricle systolic dysfunction [5]. We excluded patients with left ventricular systolic and diastolic dysfunction. The fact that we observed consistent association between BNP levels as well as increases in BNP levels supports that BNP is an excellent biomarker for diagnosing and assessing the severity of CAD.

\section{CONCLUSION}

Pre-exercise and peak exercise values as well as increases in BNP levels are associated with presence and severity of CAD among patients undergoing EST independent of left ventricular systolic dysfunction. Our findings suggest that BNP should be used more actively in management of CAD in addition to its wellestablished role in diagnosis and management of heart failure.

\section{Conflict of interest}

The authors disclosed no conflict of interest during the preparation or publication of this manuscript.

\section{Financing}

The authors disclosed that they did not receive any grant during conduction or writing of this study.

\section{REFERENCES}

[1] Kisch B. Electron microscopy of the atrium of the heart. I. Guinea pig. Exp Med Surg 1956;14:99-112.

[2] Saito Y, Nakao K, Itoh H, Yamada T, Mukoyama M, Arai H, et al. Brain natriuretic peptide is a novel cardiac hormone. Biochem Biophys Res Commun 1989;158:360-8.

[3] Levin ER, Isackson PJ, Hu RM. Endothelin increases atrial natriuretic peptide production in cultured rat diencephalic neurons. Endocrinology 1991;128:2925-30.

[4] Omland T, Persson A, Ng L, O'Brien R, Karlsson T, Herlitz $\mathrm{J}$, et al. N-terminal pro-B-type natriuretic peptide and long-term mortality in acute coronary syndromes. Circulation 2002;106:2913-8.

[5] Bibbins-Domingo K, Ansari M, Schiller NB, Massie B, Whooley MA. B-type natriuretic peptide and ischemia in patients with stable coronary disease: data from the Heart and Soul study. Circulation 2003;108:2987-92.

[6] Kikuta K, Yasue H, Yoshimura M, Morita E, Sumida H, Kato $\mathrm{H}$, et al. Increased plasma levels of B-type natriuretic peptide in patients with unstable angina. Am Heart J 1996;132(1 Pt 1):1017.

[7] Miranda CP, Liu J, Kadar A, Janosi A, Froning J, Lehmann $\mathrm{KG}$, et al. Usefulness of exercise-induced ST-segment depression in the inferior leads during exercise testing as a marker for coronary artery disease. Am J Cardiol 1992;69:303-7.

[8] Foote RS, Pearlman JD, Siegel AH, Yeo KT. Detection of exercise-induced ischemia by changes in B-type natriuretic peptides. J Am Coll Cardiol 2004;44:1980-7.

[9] Yamada H, Do D, Morise A, Atwood JE, Froelicher V. Review of studies using multivariable analysis of clinical and exercise test data to predict angiographic coronary artery disease. Prog Cardiovasc Dis 1997;39:457-81.

[10] Diamond GA, Forrester JS, Hirsch M, Staniloff HM, Vas R, Berman DS, et al. Application of conditional probability analysis to the clinical diagnosis of coronary artery disease. J Clin Invest 1980;65:1210-21.

[11] Froelicher VF, Lehmann KG, Thomas R, Goldman S, 
Morrison D, Edson R, et al. The electrocardiographic exercise test in a population with reduced workup bias: diagnostic performance, computerized interpretation, and multivariable prediction. Veterans Affairs Cooperative Study in Health Services \#016 (QUEXTA) Study Group. Quantitative Exercise Testing and Angiography. Ann Intern Med 1998;128(12 Pt 1):965-74.

[12] Bassan R, Potsch A, Maisel A, Tura B, Villacorta H, Nogueira MV, et al. B-type natriuretic peptide: a novel early blood marker of acute myocardial infarction in patients with chest pain and no ST-segment elevation. Eur Heart J 2005;26:234-40. [13] Visser CA, Lie KI, Kan G, Meltzer R, Durrer D. Detection and quantification of acute, isolated myocardial infarction by two dimensional echocardiography. Am J Cardiol 1981;47:1020-5. [14] Dagianti A, Penco M, Agati L, Sciomer S, Dagianti A, Rosanio S, et al. Stress echocardiography: comparison of exercise, dipyridamole and dobutamine in detecting and predicting the extent of coronary artery disease. J Am Coll Cardiol 1995;26:18-25.

[15] Verani MS. Pharmacologic stress myocardial perfusion imaging. Curr Prob Cardiol 1993;18:481-525.

[16] Davidson NC, Pringle SD, Pringle TH, McNeill GP, Struthers AD. Right coronary artery stenosis is associated with impaired cardiac endocrine function during exercise. Eur Heart J 1997;18:1749-54.

[17] Marumoto K, Hamada M, Hiwada K. Increased secretion of atrial and brain natriuretic peptides during acute myocardial ischaemia induced by dynamic exercise in patients with angina pectoris. Clin Sci (Lond) 1995;88:551-6.

[18] Weber M, Dill T, Arnold R, Rau M, Ekinci O, Muller KD, et al. N-terminal B-type natriuretic peptide predicts extent of coronary artery disease and ischemia in patients with stable angina pectoris. Am Heart J 2004;148:612-20. 